\title{
Gasoline Savings From Clean Vehicle Adoption
}

\section{Tamara Sheldon and Rubal Dua}

January 2018 KS-2018--DP026 


\section{About KAPSARC}

The King Abdullah Petroleum Studies and Research Center (KAPSARC) is a non-profit global institution dedicated to independent research into energy economics, policy, technology and the environment across all types of energy. KAPSARC's mandate is to advance the understanding of energy challenges and opportunities facing the world today and tomorrow, through unbiased, independent, and high-caliber research for the benefit of society. KAPSARC is located in Riyadh, Saudi Arabia.

\section{Legal Notice}

(C) Copyright 2017 King Abdullah Petroleum Studies and Research Center (KAPSARC). No portion of this document may be reproduced or utilized without the proper attribution to KAPSARC. 


\section{Key Points}

ithout the option to purchase plug-in electric and/or hybrid vehicles, conventional counterfactuals used in literature may underestimate the fuel savings from clean vehicle adoption, thus overestimating the costs of securing associated environmental benefits. Using a nationally representative sample of new car purchases in the U.S., a vehicle choice model-based counterfactual approach is proposed that allows for the prediction of what consumers would purchase if these clean vehicles were unavailable. The cost of demand-side policies in the form of financial incentives to encourage plug-in electric vehicle adoption is estimated. Our study shows that:

Gasoline consumption under a no clean vehicle scenario increases by 1.7 percent, compared with a 1.1 percent increase based on a conventional counterfactual.

Many pivotal buyers would instead purchase premium brands and larger vehicles, leading to an increase in the share of light trucks, which are subject to less stringent, but more difficult to meet, standards.

Assuming a vehicle lifetime of 10 years, the conventional counterfactual overestimates the cost of gasoline savings at $\$ 8.75$ per gallon compared with $\$ 6.90$ per gallon that is estimated from the choice model-based counterfactual. 


\section{Summary}

$\mathrm{T}$ he goal of many transportation policies is to increase clean vehicle market share.

Quantifying the benefits of these policies requires assumptions about what consumers would have purchased in the absence of the policy. For example, existing literature assumes that consumers who purchase plug-in electric vehicles (PEVs) would otherwise purchase an economy or midsize car. Without the option to purchase plug-in electric and/ or hybrid vehicles, conventional counterfactuals used in the literature may underestimate the fuel savings from clean vehicle adoption, thus overestimating the costs of securing associated environmental benefits.

A choice model of vehicle purchases based on a nationally representative sample of new U.S. vehicle purchases in model year 2015 was developed. The choice model also incorporates heterogeneity of consumer preferences across demographic and attitudinal variables. Using this model, predictions are made on the national vehicle market share at the make-model level assuming unavailability of 1) PEVs and 2) PEVs and hybrid electric vehicles (HEVs). These predictions are used to construct counterfactual fleet fuel economy and gasoline consumption for both scenarios.

In Scenario 1 when PEVs are not available, less than 5 percent of the would-be PEV buyers (who make up 0.81 percent of the total market) purchase HEVs instead. More would-be PEV buyers purchase SUVs (11 percent) and pickups (11 percent) instead. Overall, more than a quarter of the would-be PEV buyers switch to a light truck, leading to an increase in overall light truck market share (from 48.24 percent to 48.45 percent) and decrease in passenger car share (from 51.76 percent to 51.55 percent). These trends are exacerbated in Scenario 2 when HEVs are also unavailable, with light truck share increasing to 49.36 percent and passenger car share decreasing to 50.64 percent.

Results suggest that if PEVs were not available, fuel economy of cars would decrease nearly 1 percent and that of light trucks would drop by 0.23 percent for a total decline in fleet fuel economy of 0.60 percent. If PEVs and HEVs, which jointly account for 3.38 percent of the 2015 market share, were not available, fuel economy of cars would decrease by 2.49 percent and that of light trucks would drop by 0.37 percent for a total decline in fleet fuel economy of 1.68 percent. Lastly, since PEV and HEV consumers also tend to drive more miles, in the absence of clean vehicles gasoline consumption rises by 1.71 percent, greater than the decrease in fleet fuel economy.

Together, these results imply that clean vehicle adoption has led to a significant reduction in gasoline consumption. Finally, the study estimates greater increases in fuel economy and decreases in gasoline consumption relative to counterfactuals relied upon in existing literature ('conventional counterfactuals'). A simple calculation estimates that the cost of the gasoline savings resulting from PEV adoption incentives to be $\$ 6.90$ per gallon, assuming a vehicle life of 10 years. While relatively expensive, it is significantly less than the $\$ 8.75$ per gallon that is estimated using conventional counterfactuals. 


\section{Introduction}

ederal, state and local governments in the U.S. offer a variety of incentives to promote clean vehicle adoption. There is a federal tax credit for plug-in electric vehicles (PEVs) and a dozen states offer additional financial incentives to PEV buyers in the form of rebates, tax credits and sales tax exemptions. Local incentives include subsidized battery recharging stations, preferred parking and access to high occupancy vehicle lanes. These policies are generally intended to decrease carbon dioxide emissions as well as to reduce local air pollution such as sulfur dioxide and nitrogen oxides.

Recent evidence suggests consumers that are most likely to purchase advanced clean vehicles, such as PEVs, are early adopters and environmentally conscious (Sheldon, J.R. DeShazo, and Carson 2017; Dua 2017). These consumers may therefore be more likely to 'trade up' from a hybrid to a PEV, resulting in considerably lower gains than replacing a standard, internal combustion engine (ICE) vehicle with a PEV. On the other hand, luxury PEV consumers may otherwise purchase high emitting, high performance vehicles. Achieving greenhouse gas (GHG) and pollution reduction goals depend not only on clean vehicle market share but also on which vehicles are taken off the road as a result of clean vehicle sales. Failure to account for such counterfactuals may result in significant over- or underestimates of the environmental benefits of clean vehicles.

Complicating the analysis of a counterfactual fleet is the impact of Corporate Average Fuel Economy (CAFE) and the Environmental Protection Agency's recent GHG standards, which regulate carbon dioxide emissions from automobiles under the Clean Air Act. The CAFE and GHG standards set specific sales-weighted fuel economy and GHG emissions targets for automakers with the goal of improving energy use and reducing emissions. PEV sales help auto manufacturers meet CAFE standards. In a counterfactual world without PEVs, auto manufacturers would still have to meet CAFE and GHG targets, meaning that, in theory, fleet fuel economy could not decrease below the targets, at least in the medium and long run. Nevertheless, since CAFE standards vary by vehicle size, a change in the vehicle class mix could still impact fleet fuel economy. Additionally, gasoline savings from PEV adoption depends not only on which ICE vehicles are taken off the road, but also on how much those vehicles are driven.

In this paper, fuel savings from the adoption of clean vehicles is estimated. The nationally representative sample of nearly 275,000 new vehicle purchases in the U.S. in 2015 includes household level demographic and attitudinal variables. Linking these data to a database of vehicle characteristics, an innovative vehicle choice model is estimated that incorporates consumer heterogeneity, resulting in more precise market share estimates. Using this model, the national vehicle sales at the make-model level is predicted assuming unavailability of 1) PEVs and 2) PEVs and hybrid vehicles (HEVs). These predictions are then used to construct counterfactual fleet fuel economy and gasoline consumption for both scenarios. Lastly, the cost of demand-side policies in the form of financial incentives to encourage plug-in electric vehicle adoption is estimated. 


\section{Data}

he primary dataset, which was purchased from Strategic Vision Incorporated, is from a survey of households that purchased a new vehicle in model year 2015. It is a representative sample of the U.S. national new vehicle market and includes approximately 275,000 observations along with weights that correspond to the ratio of the number of buyers for each make and model in the national market to the number of respondents for the same make and model in the survey. The survey collects information on household characteristics and attitudes, as well as information on the new vehicle purchased, including the vehicle identification number (VIN). Household characteristics include respondent's age, education level, household income and number of miles the respondent intends to drive his or her new vehicle each month. Although the dataset is not statewise representative, each respondent's state of residence is known as well as whether he or she lives in a metropolitan, suburban, rural or farming area.

Although some households self-report new vehicle characteristics, to ensure accuracy of vehicle attributes, the new vehicles are matched to their characteristics on VIN using Edmunds database of vehicle characteristics. Vehicle characteristics include manufacturer's suggested retail price (MSRP), fuel economy, horsepower, fuel capacity, curb weight, wheel base, track width and body type. For PEVs, fuel economy is reported in miles per gallon (mpg) equivalent, which is the average distance traveled per unit of energy consumed normalized to the energy content of a gallon of gasoline. EPA calculations assume that in terms of energy use, 1 gallon of gasoline is equivalent to 33.7 kilowatt-hours of electricity. For PEVs, the data also include electric range. With regard to fuel economy, for the vehicle choice model this is calculated as the harmonic mean of city fuel economy and highway fuel economy, which are weighted by 55 percent and 45 percent, respectively. This is consistent with the EPA's unadjusted/laboratory combined fuel economy calculations, which are used for compliance standards and for the fuel economy labels that consumers see. However, in the counterfactual analysis of fleet fuel economy, city and highway weights of 43 percent and 57 percent, respectively, are used, which is consistent with EPA methodology for adjusted fleet fuel economy calculations and is the best estimate of real world performance. For more details see EPA (2015).

In this analysis, several constructed variables are used. For ICEs, range is calculated as the product of fuel capacity and fuel economy. Range is equal to the electric range for BEVs. For PHEVs, range is calculated as the product of fuel capacity and fuel economy, plus the electric range. Performance is defined as horsepower over curb weight.

Table 1 shows summary statistics of the new vehicles purchased in the nationally representative sample, as well as mean monthly vehicle miles traveled (VMT). For VMT calculations, the missing observations are replaced with the sampleweighted mean monthly VMT of 1,116 miles. In our analysis, PEVs include both battery electric vehicles (BEVs), which are all-electric, as well as plug-in hybrid vehicles (PHEVs), which have both an electric battery and an internal combustion engine. 
Table 1. Summary statistics.

Mean StDev

\begin{tabular}{l|l|l}
\hline Price (\$) & 30,581 & 12,335 \\
\hline Fuel economy (mpg) & 25.06 & 8.96 \\
\hline Horsepower & 232 & 85 \\
\hline Fuel capacity (gal.) & 18.4 & 5.3 \\
\hline Curb weight (Ibs) & 3,831 & 896 \\
\hline Wheel base (in.) & 113 & 13 \\
\hline Track width (in.) & 63.7 & 3.2 \\
\hline Range (mi) & 426 & 77 \\
\hline HEV & $2.57 \%$ & $15.81 \%$ \\
\hline PHEV & $0.29 \%$ & $5.41 \%$ \\
\hline BEV & $0.52 \%$ & $7.21 \%$ \\
\hline Convertible & $0.74 \%$ & $8.57 \%$ \\
\hline Coupe & $3.33 \%$ & $17.94 \%$ \\
\hline Full-Size & $0.18 \%$ & $4.22 \%$ \\
\hline Hatchback & $5.01 \%$ & $21.82 \%$ \\
\hline Minivan & $2.98 \%$ & $17 \%$ \\
\hline Pickup & $12.55 \%$ & $33.13 \%$ \\
\hline SUV & $32.79 \%$ & $46.94 \%$ \\
\hline Sedan & $34.06 \%$ & $47.39 \%$ \\
\hline Wagon & $8.35 \%$ & $27.67 \%$ \\
\hline Monthly VMT & 1,116 & 843 \\
\hline & &
\end{tabular}

Source: KAPSARC. 


\section{Vehicle Choice Model}

$\mathrm{T}$ The purpose of the vehicle choice model is to predict vehicle choices when certain alternatives are unavailable. A standard conditional logit model exhibits the independence of irrelevant alternatives (IIA) property, meaning that the odds of choosing one vehicle over another are independent of the choice set for all other pairs. For example, if the PEV alternative is removed from the choice set, the probability that had previously been allocated to choosing the PEV is split equally across remaining alternatives. This could lead to unrealistic substitution patterns, especially if PEV consumers are more likely to purchase an HEV or an SUV, for example.

The foundation of this model is the following mixed logit model. Consumer $n$ chooses the vehicle that maximizes her utility of choosing vehicle $i, U_{n i}$. Utility is a linear function of a vector of vehicle characteristics, $X_{i}$, as follows:

$$
U_{n i}=\mathbf{X}_{\mathbf{i}}^{\prime} \boldsymbol{\beta}_{\boldsymbol{n}}+\varepsilon_{n i}
$$

Assuming $\varepsilon_{n i}$ 's are independently distributed Type-I extreme value errors, the probability of individual $n$ selecting vehicle $i$ can be written as:

$$
\pi_{n i}=\int \frac{\exp \left(\mu_{n} \mathbf{X}_{\mathbf{i}}^{\prime} \boldsymbol{\beta}\right)}{\sum_{j=1}^{J} \exp \left(\mu_{n} \mathbf{X}_{\mathbf{j}}^{\prime} \boldsymbol{\beta}\right)} f(\boldsymbol{\beta} \mid \boldsymbol{\theta}) \partial \boldsymbol{\beta}
$$

where $\mu_{n}$ is a scale parameter commonly assumed to equal 1 and where $f(\beta \mid \theta)$ is the density function of $\beta$.

In contrast to the conditional logit model that assumes fixed parameters, the mixed logit allows for random parameters. When an estimate of the mixed logit model is made, the distribution of the random parameters is also estimated. However, the mixed logit does not inform how consumer characteristics correlate with the parameter distributions. While in theory the mean and/or variance of mixed logit parameters could be interacted with the consumer characteristics, such models tend not to converge to a well-defined maximum value due to numerical instability. Similar issues were encountered when attempting to estimate latent class models on this large dataset.

In order to more accurately identify heterogeneity in preferences across consumers, a "mesh" strategy is utilized where the sample is divided into subsamples (or "meshes") and for each subsample, a mixed logit on aggregate market shares for that subsample is estimated. The choice sets are at the make-modelengine type level, where engine type is either ICE, HEV, BEV or PHEV. For example, the conventional Ford Focus and the Ford Focus Electric appear as separate alternatives. This results in approximately 400 alternatives.

Table 2 shows the three variables that are used to divide the sample into meshes: 1) socio-economic group, which is a function of age, income and education; 2) pro-environmental attitude; and 3) residential location. A separate 'mesh' is generated for each socio-economic by pro-environment and by residential location group of consumers for a total of 90 meshes. Table 3 shows summary statistics of the number of observations and weighted observations in each mesh. For computational ease, the household level data is aggregated to market share level within each mesh, summing frequency weights for each make-model-engine observation such that the sample remains representative. Since each household within a mesh that chooses a particular make-model-engine is identical with respect to variables used in the estimation, estimating the mixed logit model on aggregate market shares using frequency weights is equivalent to estimating the model on individual level data. 
Table 2. Mesh categories.

\section{Socio-Economic Group}

Socio-Economic Group

Age < 35 / Income > \$70K / College

Age $<35$ / Income $>\$ 70 \mathrm{~K} /$ No college

Pro-Enviro†

Residential Location

\begin{tabular}{l|l|l}
\hline Age $<35 /$ Income $\leq \$ 70 \mathrm{~K} /$ College & & Small town or rural city \\
\hline Age $<35 /$ Income $\leq \$ 70 \mathrm{~K} /$ No college & & Farming area \\
\hline Age $35+/$ Income $>\$ 70 \mathrm{~K} /$ College & & \\
\hline Age $35+/$ Income $>\$ 70 \mathrm{~K} /$ No college & & \\
\hline Age 35 + / Income $\leq \$ 70 \mathrm{~K} /$ College & & \\
\hline Age 35 + / Income $\leq \$ 70 \mathrm{~K} /$ No college & & \\
\hline Missing & & \\
\hline
\end{tabular}

†Individual indicated he or she agrees somewhat or strongly with "I would pay significantly more for an environmentallyfriendly vehicle."

Source: KAPSARC.

Table 3. Mesh sizes.

Observations

Frequency (Weighted)

\begin{tabular}{l|l|l}
\hline Minimum $\dagger$ & 5 & 111 \\
\hline Second Min. $\dagger$ & 12 & 731 \\
\hline 25th Percentile & 378 & 15,308 \\
\hline Median & 1,174 & 57,390 \\
\hline 75 th Percentile & 2,967 & 138,907 \\
\hline Maximum & 38,981 & $1,733,866$ \\
\hline
\end{tabular}

†The smallest mesh includes observations with age $<35$ / income $>\$ 70 \mathrm{~K}$, no college, pro-environmental and missing residence. The second smallest mesh is similar except college educated. Given the limited sample sizes for these two meshes, for each of these the estimates from the most similar mesh is utilized. That is, the mesh that has identical characteristics except rather than missing residence, includes observations from suburban residences.

Source: KAPSARC. 
For most mesh estimates, vehicle characteristics in the utility function include price, fuel economy, range, performance, engine type indicators (HEV, PHEV or BEV, with ICE as the omitted category), make indicators and body type indicators (convertible, coupe, full-size car, hatchback, minivan, pickup, SUV and wagon, with sedan as the omitted category). Ultra-luxury brands are excluded to avoid skewing our estimates, since though representing a tiny market share, their prices may be outliers. These brands are also not represented by most meshes. These ultra-luxury brands include Alfa Romeo, Aston Martin, Bentley, Ferrari, Jaguar, Lamborghini, Lotus, Maserati, McLaren and RollsRoyce. Due to collinearity amongst the variables, a variable is constructed that is the product of fuel economy, range and performance scaled by price. This variable is specified to have a random parameter. To better characterize body type substitution patterns, the SUV indicator (which is the second most popular body type after sedan) is also specified to have a random parameter. A minority of mesh estimates do not converge when attempting to estimate this model, particularly for meshes with fewer observations. In these cases, the model is first simplified by considering SUV a fixed rather than a random parameter and, if convergence is still not achieved, then by excluding the make indicators.
Table 4 summarizes the three utility functions utilized in this analysis. Lastly, due to collinearity between the BEV indicator and other attributes, such indicators are excluded from the utility function in the first stage fit. Then, in a second stage the utility function is re-estimated while constraining the fuel economy-range-performance-price coefficient to equal that from the first stage and including the BEV and Tesla indicators.

For PEV prices, the MSRP is adjusted for state and national incentives. Specifically, for PHEV and BEV purchase observations from states with incentives, the MSRP is reduced by the maximum incentive amounts obtained from DeShazo (2016). These state incentives range from $\$ 500$ to $\$ 7,500$, with most falling in the $\$ 2,000-\$ 3,000$ range. The federal tax credit varies by vehicle, with a maximum amount of $\$ 7,500$ (DOE-EPA). A household cannot claim more than it pays in federal income tax. For example, if a household purchases a PEV eligible for a $\$ 7,500$ tax credit but only pays $\$ 5,000$ in federal taxes, it will get to offset the full $\$ 5,000$ of federal taxes, but will not receive an additional rebate or benefit on top of that. The PEV tax credit does not roll over and thus cannot be used to offset future taxes. Due to the complexity of estimating household federal taxes owed and the lack of

Table 4. Utility function.

\begin{tabular}{|c|c|c|c|}
\hline Utility Function & Fixed Parameters & Random Parameters & Number of Meshes \\
\hline 1 & Makes, bodies, HEV, PHEV, BEV & $\begin{array}{l}\text { SUV (Fuel } \\
\text { Economy*range* performance)/price }\end{array}$ & 58 \\
\hline 2 & Makes, bodies, HEV, BEV, PHEV & $\begin{array}{l}\text { (Fuel economy*range*performance)/ } \\
\text { price }\end{array}$ & 22 \\
\hline 3 & Bodies, HEV, BEV, PHEV & $\begin{array}{l}\text { (Fuel economy*range*performance)/ } \\
\text { price }\end{array}$ & 10 \\
\hline
\end{tabular}

Source: KAPSARC. 
necessary data to do so (e.g., precise pre-tax income, mortgage, student loan information, number of dependents, etc.), a simplifying assumption is made that all PEV purchases in the data are eligible for the maximum federal tax credit. Given the observation that most PEV buyers are high income, this is a reasonable assumption. Therefore, in addition to any state level subsidies, the PEV prices are adjusted downwards by the maximum amount of the federal tax credit available for each model.

In an effort to move inventory, many vehicle manufacturers have been offering cash rebates and special lease offers for their PEVs on top of government incentives. While these vary across vehicle, manufacturer and location, the cash rebates average around 9 percent of MSRP (Campbell, Zhou and Lin 2017). Therefore, for all PEVs, the MSRP is reduced by 9 percent before deducting federal tax credit and any state incentives. When the individual data is collapsed into aggregate market share, the weighted average price is taken across individuals.

After estimating mixed logit models for each mesh, estimation results are used to predict consumer vehicle choices separately for each mesh. Using consumer weights the separate mesh predictions are aggregated into market shares of the representative national sample. Table 5 shows the model predictions for BEV, PHEV and HEV market shares are identical to the actual market shares in the sample.

Table 5. Actual versus predicted market shares.

\begin{tabular}{l|l|l|l}
\multicolumn{2}{c}{ BEV } & PHEV & \multicolumn{2}{c}{ HEV } \\
\hline Actual & $0.52 \%$ & $0.29 \%$ & $2.57 \%$ \\
\hline Predicted & $0.52 \%$ & $0.29 \%$ & $2.57 \%$
\end{tabular}

Source: KAPSARC. 


\section{Counterfactual Analysis}

$\mathrm{T}$ The consumer vehicle choice is predicted under three different scenarios: 0 ) the actual set of available vehicles is available; 1) PEVs are not available; and 2) neither PEVs nor HEVs are available. There are two major assumptions underlying this counterfactual analysis. The vehicle choice model bases consumer choice conditional upon having decided to purchase a new vehicle. Currently, it is not possible to include an outside option to not purchase a new vehicle in this study. Thus, our counterfactual analysis assumes that the total number of new vehicle purchases is the same - i.e., when PEVs and/or HEVs are not available, the same population still decides to purchase a new vehicle. This is a reasonable assumption because although a household might delay purchasing a new vehicle as they anticipate the arrival of a particular model (e.g., the Tesla Model 3), in a counterfactual world devoid of PEVs or HEVs, a household would not have these models to anticipate.
The second assumption is that in the counterfactual scenarios, prices of available vehicles are unchanged - i.e., only the demand side is modeled, not the supply side. Langford et al. (Langford and Gillingham 2015) model both the supply and demand sides of the new vehicle market for their counterfactual analysis. They find that if hybrids were not available from 2001-2008, equilibrium prices of close substitutes would be lower. However, Table 3 of their paper shows a maximum price decrease of $\$ 18$. Such small price changes are unlikely to significantly change the counterfactual analysis results.

Table 6 shows market share estimates for various vehicle types under each scenario. In Scenario 1 when PEVs are not available, less than 5 percent of the would-be PEV buyers (who make up 0.81 percent of the total market) purchase HEVs instead. More would-be PEV buyers purchase SUVs (11

Table 6. Market shares, fuel economy and gasoline consumption of counterfactual scenarios.

\begin{tabular}{l|l|l|l}
\multicolumn{1}{l}{ Scenario 0 Predicted } & \multicolumn{1}{l}{ Scenario 1 No PEVs } & Scenario 2 No PEVs or HEVs \\
\hline HEV & $2.57 \%$ & $2.61 \%$ & $33.2 \%$ \\
\hline SUV & $32.7 \%$ & $32.8 \%$ & $0.8 \%$ \\
\hline Convertible & $0.8 \%$ & $0.8 \%$ & $3.5 \%$ \\
\hline Full size car & $3.4 \%$ & $3.4 \%$ & $0.2 \%$ \\
\hline Hatchback & $0.2 \%$ & $0.2 \%$ & $5.0 \%$ \\
\hline Minivan & $5.3 \%$ & $5.1 \%$ & $3.1 \%$ \\
\hline Pickup & $3.0 \%$ & $3.0 \%$ & $13.0 \%$ \\
\hline Sedan & $12.6 \%$ & $12.7 \%$ & $32.6 \%$ \\
\hline Wagon & $33.6 \%$ & $33.6 \%$ & $8.6 \%$ \\
\hline Passenger car share & $8.5 \%$ & $8.5 \%$ & $50.64 \%$ \\
\hline Light truck share & $51.76 \%$ & $51.55 \%$ & $49.36 \%$ \\
\hline MPG passenger cars & $48.24 \%$ & $48.45 \%$ & 28.09 \\
\hline MPG light trucks & 28.81 & 28.55 & 19.51 \\
\hline MPG fleet & 19.58 & 19.53 & 23.08 \\
\hline Annual billion gal. of gasoline & 7.14 & 23.33 & 7.26 \\
\hline
\end{tabular}

Source: KAPSARC. 
percent) and pickups (11 percent) instead. Overall, more than a quarter of the would-be PEV buyers switch to a light truck, leading to an increase in overall light truck market share (from 48.24 percent to 48.45 percent) and a decrease in passenger car share (from 51.76 percent to 51.55 percent). These trends are exacerbated in Scenario 2 when HEVs are also unavailable, with light truck share increasing to 49.36 percent and passenger car share decreasing to 50.64 percent.

Table 7 shows market shares of different makes in each of the three scenarios. From Scenario 0 to
Scenario 1, where PEVs are no longer available, market shares of makes with popular PEV models such as Chevrolet (maker of the Volt), Ford (maker of the C-MAX Energi, Fusion Energi and Focus Electric) and Toyota (maker of the Prius plug-in) decline. Nissan's predicted market share actually increases from Scenario 0 to Scenario 1, despite the popularity of the Nissan Leaf, which is no longer available in Scenario 1. This suggests that some would-be PEV buyers switch to other non-PEV Nissan models. Similarly, Cadillac and MercedesBenz market shares increase slightly and BMW's remains the same despite several PEVs of these

Table 7. Brand market shares (percent) of counterfactual scenarios.

\begin{tabular}{|c|c|c|c|}
\hline & Scenario 0 Predicted & Scenario 1 No PEVs & Scenario 2 No PEVs or HEVs \\
\hline Acura & 0.83 & 0.84 & 0.85 \\
\hline Audi & 1.30 & 1.32 & 1.35 \\
\hline BMW & 2.11 & 2.11 & 2.16 \\
\hline Buick & 1.36 & 1.37 & 1.40 \\
\hline Cadillac & 0.99 & 1.00 & 1.02 \\
\hline Chevrolet & 9.00 & 8.98 & 9.20 \\
\hline Chrysler & 1.56 & 1.57 & 1.62 \\
\hline Dodge & 2.73 & 2.74 & 2.80 \\
\hline FIAT & 0.27 & 0.26 & 0.27 \\
\hline Ford & 10.96 & 10.91 & 10.96 \\
\hline GMC & 3.07 & 3.10 & 3.17 \\
\hline Honda & 10.66 & 10.60 & 10.06 \\
\hline Hyundai & 4.46 & 4.49 & 4.51 \\
\hline INFINITI & 0.85 & 0.86 & 0.85 \\
\hline Jeep & 5.31 & 5.34 & 5.44 \\
\hline Kia & 3.92 & 3.93 & 3.98 \\
\hline Land Rover & 0.04 & 0.04 & 0.04 \\
\hline Lexus & 2.38 & 2.41 & 2.34 \\
\hline Lincoln & 0.65 & 0.65 & 0.66 \\
\hline MINI & 0.41 & 0.41 & 0.43 \\
\hline Mazda & 2.20 & 2.23 & 2.29 \\
\hline Mercedes-Benz & 2.20 & 2.21 & 2.26 \\
\hline Mitsubishi & 0.50 & 0.50 & 0.51 \\
\hline Nissan & 7.93 & 7.96 & 8.15 \\
\hline Porsche & 0.74 & 0.73 & 0.75 \\
\hline
\end{tabular}

Source: KAPSARC. 
makes no longer being available in Scenario 1. This is consistent with larger increases in market share of several premium brands, including Audi and Lexus. Jeep and Subaru, whose popular models are SUVs, also have larger increases in market share.

Together, the top panel of Table 6 and Table 7 suggest that while some would-be PEV buyers switch to HEVs and other small cars, many instead switch to larger vehicles including SUVs and light trucks, as well as premium makes, which tend to have lower fuel economy.

Similar patterns emerge for Scenario 2 in Table 7. When HEVs are also unavailable, Toyota and Honda, makers of popular HEVs, have significant market share declines. Market shares of makers of larger vehicles increase (e.g., GMC, Jeep and Subaru). However, unlike Scenario 1, market shares of nonpremium brands such as Chevrolet and Nissan increase more than those of premium brands. This suggests that while many would-be PEV and HEV buyers substitute toward larger vehicles, substitution toward premium brands is driven by would-be PEV buyers.

For each scenario the predicted fleet is used to calculate the vehicle-weighted fleet fuel economy, as shown in the bottom panel of Table 6. In Scenario 0 , predicted fleet fuel economy is $23.47 \mathrm{mpg}$. In Scenario 1, when PEVs are removed from the choice set, predicted fleet fuel economy declines by 0.60 percent to $23.33 \mathrm{mpg}$. In Scenario 2, when both PEVs and HEVs are removed from the choice set, predicted fleet fuel economy declines by 1.68 percent from Scenario 0 to $23.08 \mathrm{mpg}$. To put these changes in perspective, recall that in 2015 , PEVs accounted for 0.81 percent of the market and HEVs for 2.57 percent.

For Scenarios 1 and 2, calculations are also made for a 'conventional' counterfactual generated similar to counterfactuals currently used in the literature and policy analysis to show how our results differ when a more sophisticated choice model is used to generate the counterfactuals. The conventional fuel economy counterfactuals assume that if BEVs, PHEVs or HEVs are unavailable, they are replaced by a vehicle with the average fuel economy of that BEV/PHEV/ HEV's size (e.g., compact, mid-size or full-size) and class (e.g., car, pickup or SUV). In Scenario 1, the conventional counterfactual predicts a 0.48 percent decrease in fleet fuel economy relative to the 0.60 percent estimate. In Scenario 2, the conventional counterfactual predicts a 1.12 percent decrease in fleet fuel economy relative to the 1.68 percent estimate.

The model predicts larger decrease in fleet fuel economy mainly because the conventional counterfactuals do not allow would-be PEV drivers to switch vehicle class. Most PEVs are compact or midsize cars. The conventional counterfactuals assume that if the PEVs or HEVs are not available, these consumers would choose compact or midsize ICEs. However, the vehicle choice model suggests that in the absence of their preferred PEV or HEV, many consumers would instead purchase a larger vehicle (or a premium vehicle), which typically have lower gas mileage than compact or midsize ICEs. This difference suggests that conventional counterfactuals such as those used in existing literature underestimate the fuel economy improvements from PEVs and HEVs.

Using the predicted fleet and reported monthly miles driven, the total annual gasoline consumption of the new vehicle fleet is calculated for each scenario as shown in the bottom panel of Table 6 . Annual gasoline consumption in Scenario 1 is 0.61 percent greater than Scenario 0 ( 7.18 versus 7.14 billion gallons). Annual gasoline consumption in Scenario 2 is 1.71 percent greater than Scenario 0 (7.26 
versus 7.14 billion gallons). In other words, the model predicts that if PEVs were unavailable, the fleet would consume 0.61 percent more gasoline, and if HEVs also were unavailable, the fleet would consume 1.71 percent more gasoline.

Annual gasoline consumption values for Scenarios 1 and 2 are calculated using the conventional fuel economy counterfactuals and the sample-weighted mean VMT of 1,116 miles per month (as existing studies, lacking individual data, typically rely on population averages). In Scenario 1, the conventional counterfactual predicts a 0.49 percent increase in annual gasoline consumption relative to our 0.61 percent estimate. In Scenario 2, the conventional counterfactual predicts a 1.14 percent increase in annual gasoline consumption relative to the 1.71 percent estimated from the choice model-based counterfactual.

Thus, when accounting for heterogeneous vehicle preferences and substitution patterns, predicted gasoline savings from PEV and HEV adoption are 25 percent and 50 percent greater, respectively, than the conventional counterfactuals suggest. This difference is due to the larger decrease in fleet fuel economy in the predicted scenarios relative to the conventional counterfactuals. If more PEV drivers switch to light trucks instead of midsize cars, for example, then gasoline consumption would be greater.

Gasoline consumption according to the model increase by slightly more than the decrease in the fleet fuel economy ( 0.61 percent relative to 0.60 percent and 1.71 percent relative to 1.68 percent). This is because PEV and HEV drivers tend to drive more miles. Table 8 shows the number of miles that households intend to drive their newly purchased vehicle, broken down by vehicle type. The average BEV and PHEV drivers' average monthly VMT are 5-6 percent greater than the average ICE driver, and the average HEV driver's VMT is more than 4 percent greater than the average ICE driver. Thus, when a would-be PEV or HEV driver instead purchases an ICE, this vehicle not only gets lower gas mileage, but is also driven more than the average ICE.

\section{Fuel Savings From PEV Adoption Incentives}

Many states offer financial incentives for PEV adoption in addition to the federal tax credit of up to $\$ 7,500$. Using estimates from the vehicle choice model, prices are adjusted by removing the state

Table 6. Miles driven per month by fuel type.

\begin{tabular}{l|l|l} 
& Mean & StDev \\
All & 1,116 & 843 \\
\hline ICE & 1,114 & 832 \\
\hline HEV & 1,160 & 984 \\
\hline BEV & 1,181 & 1437 \\
\hline PHEV & 1,167 & 1340
\end{tabular}

Source: KAPSARC. 
and federal incentives previously added and predict PEV sales. Absent these incentives, PEV market share decreases from 0.81 to 0.59 percent. This suggests that $(0.81-0.59) / 0.81=27$ percent of PEV sales, and therefore 27 percent of the gasoline savings from Scenario 1, are a result of PEV incentives. The total policy cost is defined as the sum of all state and federal incentives, assuming all PEVs received incentives for which they were eligible. Dividing the total policy cost by gasoline savings resulting from the policy (27 percent of gasoline savings from Scenario 1) equals $\$ 69$ per gallon of annual gasoline savings. Assuming a vehicle lifetime of 10 years, this cost decreases to $\$ 6.90$ per gallon. This is nearly $\$ 2$ per gallon less expensive than the $\$ 8.75$ per gallon that is calculated using the conventional counterfactual. Nevertheless, despite the significant environmental benefits from PEV adoption, demand-side policy costs appear to be relatively expensive.

\section{Caveat: CAFE/GHG standards}

As shown in Table 6, the model predicts that if PEVs and HEVs were not available in 2015, average fuel economy for the fleet of new vehicles would be lower and gasoline consumption higher. One caveat is that these may only represent short-run effects because, without PEVs to sell, some vehicle manufacturers may adjust supply (e.g., putting fuel savings technology on more models or lowering the price of more fuel efficient models) in order to comply with CAFE/GHG standards. Such supply responses would increase the fleet fuel economy in the long run.

The 2015 CAFE standards and compliance of the nationally representative sample is calculated based on official methodology (EPA-NHTSA 2012). Fuel economy values in the data are adjusted, unlike the laboratory performance test results used to evaluate regulatory compliance. Gillis et al.
(2016) estimate that a CAFE test score of $54.5 \mathrm{mpg}$ would correspond to an EPA consumer label of 40 mpg. Accordingly, a conversion factor of 54.5/40 = 1.3625 is used to convert the fuel economy values for use in the CAFE compliance calculations. While several automakers are non-compliant in 2015, none of the automakers would change to noncompliant in either of the counterfactual scenarios. Therefore, the fuel savings from PEVs and HEVs can be seen as additional to those from CAFE standards.

Even if some manufacturers became non-compliant in the counterfactual scenarios, fleet fuel economy would still be lower because many would-be PEV buyers would purchase light trucks instead, as shown in Table 6. CAFE/GHG standards are size-based standards and are less stringent for larger vehicles. A shift in the vehicle mix toward light trucks would result in a larger share of vehicles being subject to less stringent, but difficult to meet, standards. Furthermore, CAFE/GHG standards only regulate fleet fuel economy, not gasoline consumption. If would-be PEV drivers with high VMT purchase less fuel efficient vehicles, their increase in gasoline consumption will not be offset by lower VMT drivers buying slightly more fuel efficient vehicles as a result of CAFE/GHG standards.

\section{Caveat: The rebound effect}

The estimates of changes in gasoline consumption implicitly assume that drivers of PEVs drive the same number of miles, regardless if they drive the PEV or alternative ICE vehicle. In other words, zero rebound effect is assumed. If there is a rebound effect, these drivers may increase their vehicle miles traveled when adopting the PEV, suggesting that miles traveled on the ICE substitute could be lower, which would reduce the gasoline savings from PEVs. However, if there is a rebound effect, it is likely to be small. 
Gillingham (2014) estimates a rebound effect of 9 percent for Californian households in the period 2000-2006. Small and Van Dender (2007) find that the rebound effect for motor vehicle travel in the U.S. has been declining over time and is decreasing with income. With income at 1997-2001 levels they estimate a short- and long-run rebound effect of 3.1 percent and 15.3 percent, respectively. Literature on consumer residential energy demand also suggests the rebound effect is declining in income (Henly, Ruderman and Levine 1988; Reiss and White 2005). Since PEV drivers tend to be high income earners, any rebound effect is likely to be on the low end.

In an analysis of the 2009 federal Cash for Clunkers program, West et al. (2017) find that while households did purchase more fuel efficient vehicles as a result of the scrappage program, despite a lower cost per mile due to an increase in fuel economy, households did not respond by increasing miles driven. Gillingham et al. (2015) who estimate a gasoline price elasticity of -0.1 , find that this elasticity is driven by low fuel economy vehicle drivers. They find that higher fuel economy vehicles' miles traveled are highly inelastic to changes in the gasoline price and that newer vehicles are also less responsive. Since PEV consumers tend to have high incomes and since new vehicle sales are analyzed, consumers who are 'switching' in the counterfactual case are likely to have inelastic price elasticities of demand for VMT. As such, any potential rebound effect is likely to be very small. 


\section{Conclusion}

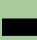

0

ur study shows that if PEVs and HEVs were not available, fleet fuel economy would decrease. Many clean vehicle

buyers would instead purchase larger vehicles, leading to a shift in the vehicle class mix. Would-be PEV buyers would also substitute toward premium brands, which tend to have lower fuel economy. Also, since PEV and HEV consumers also tend to drive more miles, in the absence of clean vehicles, gasoline consumption rises by slightly more than the decline in fleet fuel economy. Together, these results imply that clean vehicle technology has led to a significant reduction in gasoline consumption and will continue to do so in the near future despite potential leakage from CAFE and GHG regulations. The estimates of fuel economy improvements and gasoline savings from PEVs are larger than conventional back of the envelope calculations, suggesting that recent estimates of environmental benefits of PEVs may be underestimated. Finally, the results imply that PEV adoption incentives cost $\$ 6.90$ per gallon of gasoline saved, assuming a vehicle lifetime of 10 years, suggesting need for improvement in the cost-effectiveness of current demand-side measures to support PEV adoption. 


\section{References}

Campbell, Russell, Yan Zhou and Zhenhong Lin. 2017. Analysis of Manufacturer Plug-In Electric Vehicle Incentives. In Transportation Research Board Annual Meeting Compendium of Papers.

DeShazo, JR. 2016. "Improving Incentives for Clean Vehicle Purchases in the United States: Challenges and Opportunities." Review of Environmental Economics and Policy No. 10 (1):149-165.

DOE-EPA. Federal Tax Credits for All-Electric and Plug-in Hybrid Vehicles. Available from https://www. fueleconomy.gov/feg/taxevb.shtml

Dua, R., K. White, and R. Lindland. 2017. Understanding Potential for Battery Electric Vehicle Adoption Using Large-Scale Consumer Profile Data. In Transportation Research Board Annual Meeting Compendium of Papers.

EPA-NHTSA. 2017 and Later Model Year LightDuty Vehicle Greenhouse Gas Emissions and Corporate Average Fuel Economy Standards 2012. Available from https://www.federalregister.gov/ documents/2011/12/01/2011-30358/2017-and-later-modelyear-light-duty-vehicle-greenhouse-gas-emissions-andcorporate-average-fuel

EPA. Light-Duty Automotive Technology, Carbon Dioxide Emissions and Fuel Economy Trends: 1975 Through 2015. Available from https://www.epa.gov/ fuel-economy-trends/trends-report

Gillingham, Kenneth. 2014. "Identifying the elasticity of driving: evidence from a gasoline price shock in California." Regional Science and Urban Economics no. 47:13-24.
Gillingham, Kenneth, Alan Jenn and Inês ML Azevedo. 2015. "Heterogeneity in the response to gasoline prices: Evidence from Pennsylvania and implications for the rebound effect." Energy Economics no. 52:S41-S52.

Gillis, Jack, Stephen Brobeck and Mark Cooper. Automakers are on the road to meeting fuel efficiency standards. 2016. Available from https://consumerfed. org/wp-content/uploads/2016/04/2016-Fuel-EconomyReport-April-25-2016.pdf

Henly, John, Henry Ruderman and Mark D Levine. 1988. "Energy saving resulting from the adoption of more efficient appliances: a follow-up." The Energy Journal No. 9 (2):163-170.

Langford, Richard P. and Kenneth Gillingham. 2015.

"Market Benefits from Hybrids." Working Paper.

Reiss, Peter C and Matthew W White. 2005. "Household electricity demand, revisited." The Review of Economic Studies no. 72 (3):853-883.

Sheldon, Tamara L., J.R. DeShazo and Richard T. Carson. 2017. "Demand for Battery-electric and Plug-in Hybrid Vehicles: Policy Lessons for an Emerging Market." Economic Inquiry no. 55(2):695-713.

Small, Kenneth A and Kurt Van Dender. 2007. "Fuel efficiency and motor vehicle travel: the declining rebound effect." The Energy Journal:25-51.

West, Jeremy, Mark Hoekstra, Jonathan Meer and Steven L Puller. 2017. "Vehicle miles (not) traveled: Fuel economy requirements, vehicle characteristics and household driving." Journal of Public Economics no. 145:65-81. 
Notes

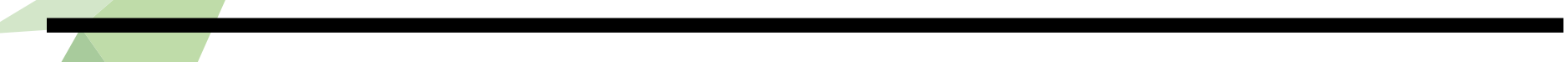




\section{About the Authors}

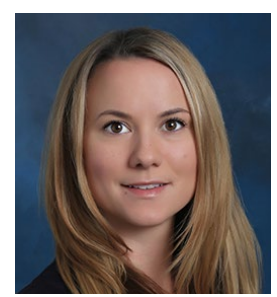

\section{Tamara Sheldon}

Tamara is a visiting researcher at KAPSARC and an assistant professor of economics in the Darla Moore School of Business at the University of South Carolina. Her research interests include environmental and energy economics and how these fields interact with public policy. She holds a Ph.D. in Economics from the University of California, San Diego.

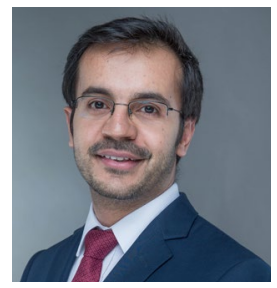

\section{Rubal Dua}

Rubal is a senior research associate at KAPSARC, working on vehicle regulatory policy and shared mobility research using the consumer perspective. He holds a Ph.D. degree from KAUST, Saudi Arabia, an M.S. degree from University of Pennsylvania, USA and a B. Tech. degree from IIT Roorkee, India.

\section{About the Project}

Promoting adoption of energy-efficient vehicles has become a key policy imperative in both developed and developing countries. Understanding the impact of various factors that affect adoption rates, such as: (i) consumer related factors - demographics, behavioral, psychographics; (ii) regulatory factors - policies, incentives, rebates, perks; and (iii) geo-temporal factors - weather, infrastructure, network effects; forms the backbone of KAPSARC's efforts in the light-duty vehicle demand field. Our team is currently developing models at different levels of resolution - micro level models using large-scale data comprising of new car buyers' profiles and macro level models using aggregated adoption data - to understand and project the effects of various factors at play for the adoption of energy-efficient vehicles. 
INAPSARC

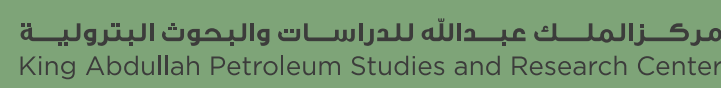

www.kapsarc.org 